\title{
Mechanical Analysis for AL5052 Joined by Mechanical Clinching
}

\author{
Yulin $\mathrm{He}^{\mathrm{a}}$, Zhengzhao Xu \\ Faculty of Mechanical \& Electrical Engineering, Guilin University of Electronic Technology, \\ Guilin, Guangxi, 541004, China \\ ahyl_2005@126.com, b502349864@qq.com
}

Keywords: AL5052 sheet; Clinching joint; Mechanical analysis; Strength

Abstract. This paper conducts correctly the mechanical analysis of joints by clinching for various values of module and process parameter. The force of tensile and shearing of the joint by clinching in AL5052 sheets were analyzed; the theoretical calculation formulas of the shearing and tensile force were deduced based on plastic forming principle. Then the clinching process was carried out by FEM simulation and experiment; the joint strength was obtained by shearing and tensile test. The results of strength tests of the joint were consistent with those obtained for theoretical calculation.

\section{Introduction}

Clinching is a metalworking process by which two or more metal sheets are joined locally without the employment of additional elements, coated or un-wieldable sheets can be joined without damaging the surface and it also suitable for those applications where a good corrosion resistance is required. Because of its' advantages and the flexibility, the clinching process has been widely utilized in in a wide range of applications, especially in automobile panel [1].

In order to guarantee the required strength of clinched joints, the technology parameters and die parameters of the clinching process, the mechanical properties of joints have been studied by scholars at home and abroad. The mechanical properties of joints depend mainly on the connection point of the neck thickness and undercut, and closely related to various parameters of clinching. Several characterization tests have been utilized, e.g. tensile tests on Hshaped samples, shear tests, fatigue tests and also impact tests [2]. In this paper, the theory calculation formulas of tensile strength and shearing strength of the connection points are derived based on the principle of plastic forming. Formulas are verified by tests, which have certain reference values for the further research of clinching process.

\section{Model and Analysis of Joint}

Clinching process is a mechanical pressure riveting process. During the process of forming, the sheet does not require to be washed, at the same time, the surface quality of clinching joint has certain requirements, to ensure the strength and good mechanical self-locking of clinching joints, the neck thickness and undercut should be sufficient [3]. The section and parameters of clinching joint are shown in Fig. 1: the punch diameter $(d)$, the neck thickness $\left(T_{\mathrm{n}}\right)$, the undercut $\left(T_{\mathrm{u}}\right)$, the die bed depth $(h)$, bottom of the die diameter $(D)$, the thickness of the connection point at the bottom $(X)$, the corner radius of the die sectors and the punch corner radius $(R)$, the upper sheets thickness $\left(t_{1}\right)$ and the lower sheets thickness $\left(t_{2}\right)$. 


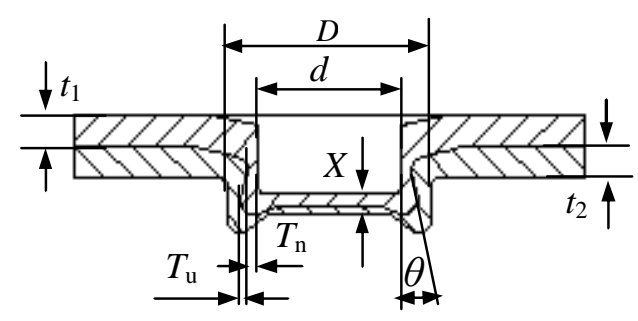

Fig. 1 Main parameters of clinching joint

In order to measure the quality of clinching joint, some people put forward the quality evaluation index, such as static strength, dynamic fatigue strength, anti-corrosion performance, the appearance of the join point, etc. But as the connection quality refers to the static strength, it has a very strong direction. According to the different load conditions, the static strength divides into tensile strength and shearing strength. The tensile strength refers to the maximum load that the clinching point to withstand the load perpendicular to the sheets, and the shearing strength refers to the maximum load that the clinching point to withstand the load parallel to sheets.

The parameters have significant influence on the strength of clinching joint. When the values of undercut, neck thickness or t bottom thickness is too small, the clinching joint will produce stripping or shearing failure under different load, it is necessary to analyze the relationship between parameters and force of the clinching point.

\section{Mechanical Analysis of Joints}

The actual strength of the clinching joint can be obtained by destructive test. Relevant data shows that the calculation of clinching joint strength is very difficult. The good results are just under some of specific conditions. In this paper, based on the principle of plastic forming, the force of clinching point was analyzed respectively under the shear load and the tensile load; the relevant calculation formulas were derived.

Shearing Force $\left(\boldsymbol{F}_{\mathrm{s}}\right)$. The clinched point under transverse shear load is shown in Fig. 2, the main failure form is shearing failure.

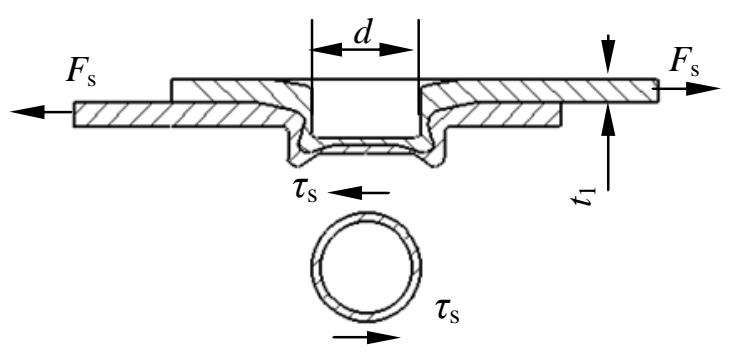

Fig. 2 The point under transverse shearing load

The corresponding transverse shearing force is defined in Eq.1.

$$
F_{s}=\pi\left[\left(T_{\mathrm{n}}+\frac{d}{2}\right)^{2}-\left(\frac{d}{2}\right)^{2}\right] \tau_{s}=\frac{\pi \sigma_{s}}{\sqrt{3}}\left(T_{\mathrm{n}}^{2}+T_{\mathrm{n}} d\right)
$$

Where $\tau_{\mathrm{s}}$ is the shearing strength, $\sigma_{\mathrm{s}}$ is the yield strength of sheet after hardening, as shown in Eq.2.

$$
\sigma_{\mathrm{s}}=278.85\left[\left(t_{1}-T_{n}\right) / t_{1}\right]^{0.0827}
$$

Tensile Force. The main failure forms of clinching point are stripping and cutting. Stripping 
failure and shearing failure are associated with undercut and neck thickness respectively. The forces on the two kinds of failure modes were analyzed and calculated.

Fig. 3 shows that two typical failure forms of the clinching point under longitudinal tensile load, Fig. 3 (a) is stripping failure mode, Fig. 3 (b) is shearing failure mode.

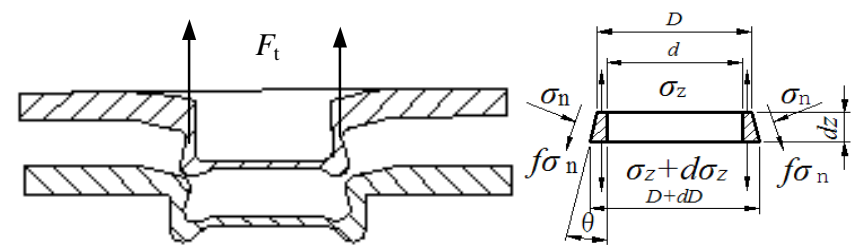

(a) Stripping failure

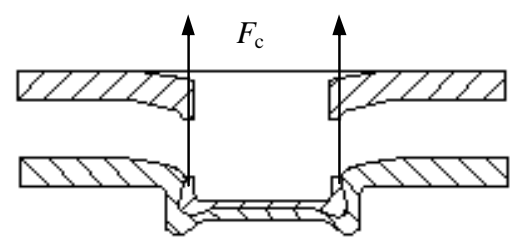

(b) Shearing failure

Fig. 3 The point under longitudinal tensile load

In Fig. 3 (a), the thickness element dz was taken in the longitudinal deformation area, and established the equilibrium differential equation according to the stress components of the $\mathrm{Z}$ direction, the Eq.3 can be written as:

$$
\frac{1}{4} \pi\left(\sigma_{z}+d \sigma_{z}\right)\left[(D+d D)^{2}-d^{2}\right]+\pi D f \sigma_{n} d z+\pi D \sigma_{n} \tan \theta d z=\frac{1}{4} \pi \sigma_{z}\left(D^{2}-d^{2}\right)
$$

Where $\pi D f \sigma_{n} d z$ is the friction component and $\pi D \sigma_{n} \tan \theta d z$ is the positive pressure component of ring peripheral surface in the direction of $Z$, the Eq.4 can be written as:

$$
2 \sigma_{\mathrm{n}}\left(\frac{f}{\tan \theta}+1\right) D d D+2 D \sigma_{s} d D-d^{2} d \sigma_{z}=0
$$

Where $\sigma_{\mathrm{z}}$ is compressive stress, $\sigma_{\mathrm{n}}$ is negative stress, $\sigma_{\mathrm{s}}$ is yield strength of sheet. Because the $\theta$ and friction coefficient $f$ are relatively small, the metal deformation is uniform in the deformation zone along axis $Z$, following the Trasca yield criterion, $\sigma_{z}+\sigma_{n}=\sigma_{s}$, the Eq. 5 can be written as:

$$
\frac{d \sigma_{z}}{\frac{f}{\tan \theta} \sigma_{z}-\left(\frac{f}{\tan \theta}+1\right) \sigma_{s}}=\frac{2 D d D}{D^{2}-d^{2}}
$$

And then to simplify Eq. 5 on both sides, the Eq. 6 can be written as:

$$
\frac{\tan \theta}{f} \ln \left[\frac{f}{\tan \theta} \sigma_{z}-\left(1+\frac{f}{\tan \theta}\right) \sigma_{s}\right]=\ln \left(D^{2}-d^{2}\right)+c
$$

When $D=d+2 T_{\mathrm{n}}+2 T_{\mathrm{u}}, \sigma_{\mathrm{z}}=0$, the Eq.7 can be obtained as:

$$
\frac{\tan \theta}{f} \ln \left[-\left(1+\frac{f}{\tan \theta}\right) \sigma_{s}\right]=\ln \left[\left(d+2 T_{n}+2 T_{\mathrm{u}}\right)^{2}-d^{2}\right]+c
$$

When $D=d+2 T_{n}$, simultaneous Eq 6 and $\mathrm{Eq} \mathrm{7,} \sigma_{\mathrm{z}}$ of compressive stress can be obtained as:

$$
\sigma_{z}=\sigma_{s}\left(\frac{\tan \theta+f}{f}\right)\left\{1-\left[\frac{\left(d+2 T_{n}\right)^{2}-d^{2}}{\left(d+2 T_{n}+2 T_{u}\right)^{2}-d^{2}}\right]^{\frac{f}{\tan \theta}}\right\}
$$


Where, $\sigma_{s}=278.85\left(\frac{t_{1}+t_{2}-X}{t_{1}+t_{2}}\right)^{0.0827}$, clinching joint produced stripping failure. When the joint generated shearing failure, then got $F_{\mathrm{t}}$ of the longitudinal tensile force as shown in the Eq.9.

$$
F_{\mathrm{t}}=\frac{\pi}{4}\left[\left(d+2 T_{n}\right)^{2}-d^{2}\right] \sigma_{z}
$$

When the joint generates shearing failure under longitudinal tensile load, the tensile force $F_{\mathrm{c}}$ can be obtained as:

$$
F_{\mathrm{c}}=\sigma_{\mathrm{z}} \times \frac{\pi}{4}\left[\left(d+2 T_{n}\right)^{2}-d^{2}\right]
$$

Where $\sigma_{\mathrm{z}}$ is yield strength of the sheet.

\section{Finite Element Simulation}

In order to verify the theoretical calculation formula, the clinching process for AL5052 sheets had been simulated by use of the finite element numerical simulation software DEFORM-2D.

As shown in Fig. 1, the parameters considered in the analysis were reported as follow[4,5]: $d=$ $5 \mathrm{~mm}, 5.3 \mathrm{~mm}, 5.6 \mathrm{~mm}, 5.9 \mathrm{~mm}$, respectively, $D=8 \mathrm{~mm}, h=1.4 \mathrm{~mm}, R=0.3 \mathrm{~mm}, X=0.7 \mathrm{~mm}, t=t_{1}=$ $t_{2}=1.2 \mathrm{~mm}$, bottom of die surface diameter $D_{1}=5 \mathrm{~mm}$, which were chosen to cover a relatively wide range of combinations. The friction coefficient was 0.12 between sheets, and the friction coefficient was 0.15 between molds and sheets, the pressure on the holders $(500 \mathrm{~N})$ and the speed of punch $(25$ $\mathrm{mm} / \mathrm{s}$ ) were kept constant among the simulations.

The forming processes of different punch diameters are simulated. In the postprocessor, the minimum neck thickness node coordinates $\mathrm{A}\left(X_{1}, Y_{1}\right)$ and the maximum undercut node coordinates $\mathrm{B}\left(X_{2}, Y_{2}\right)$ of the clinched joint are respectively found at the last step of the forming. The values of $T_{\mathrm{n}}, T_{\mathrm{u}}$ and $\tan \theta$ can be got from the formulas of $T_{\mathrm{n}}=\left(X_{1}-d\right)$ and $T_{\mathrm{u}}=\left(X_{2}-d\right), \tan \theta=\left(X_{1}-X_{2}\right) /\left(Y_{1}-\right.$ $\left.Y_{2}\right)$, then take the minimum calculation results of them into Eq.1, Eq.9 and Eq.10 respectively, the theoretical values of tensile force $\left(F_{\mathrm{s}}\right)$ and shearing force $\left(F_{\mathrm{t}}\right)$ can be obtained.The simulation values of $T_{\mathrm{n}}, T_{\mathrm{u}}, \tan \theta, F_{\mathrm{s}}$ and $F_{\mathrm{t}}$ shows in Table 1.

Table 1 The simulation values of $T_{\mathrm{n}}, T_{\mathrm{u}}, \tan \theta, F_{\mathrm{s}}$ and $F_{\mathrm{t}}$

\begin{tabular}{ccccccc}
\hline$d / \mathrm{mm}$ & $T_{\mathrm{n}} / \mathrm{mm}$ & $T_{\mathrm{u}} / \mathrm{mm}$ & $\tan \theta$ & $F_{\mathrm{s}} / \mathrm{N}$ & $F_{\mathrm{t}} / \mathrm{N}$ & Failure \\
\hline 5.0 & 0.37 & 0.22 & 0.25 & 977.15 & 1125.18 & \\
5.3 & 0.34 & 0.25 & 0.25 & 943.06 & 1257.66 & stripping \\
5.6 & 0.29 & 0.27 & 0.25 & 843.98 & 1343.91 & \\
5.9 & 0.24 & 0.31 & 0.26 & 731.34 & 1266.67 & shearing \\
\hline
\end{tabular}

\section{Experimental Research}

In order to verify theoretical calculation formula, the technological experiment and mechanical tests were conducted, and the analysis programs of experiment were consistent with the theoretical analysis programs. The experimental setup structure is illustrated in Fig. 4, the tensile test fixture is shown in Fig. 5. 


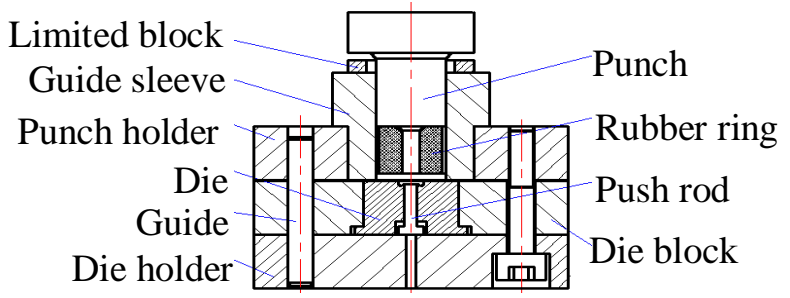

Fig.4 Setup of experiment

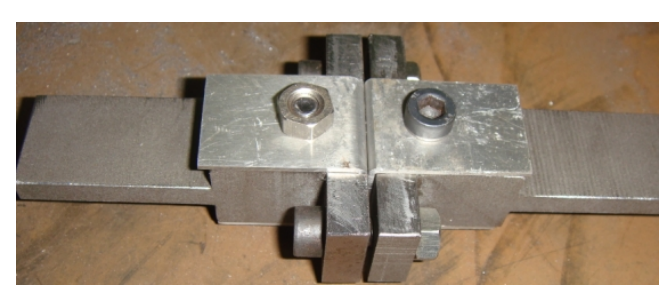

Fig.5 Fixture of tensile test

In order to ensure the accuracy of experimental results, take three sample to test, each time to measure the value of each sample and then the next, and calculate an average of the three. Finally, the experimental average values of $T_{\mathrm{n}}, T_{\mathrm{u}}, F_{\mathrm{s}}$ and $F_{\mathrm{t}}$ are shown in Table 2.

Table 2 The experimental average values of $T_{\mathrm{n}}, T_{\mathrm{u}}, F_{\mathrm{s}}$ and $F_{\mathrm{t}}$

\begin{tabular}{ccccc}
\hline$d / \mathrm{mm}$ & $\overline{T_{\mathrm{n}}} / \mathrm{mm}$ & $\overline{T_{\mathrm{u}}} / \mathrm{mm}$ & $\overline{F_{s}} / \mathrm{N}$ & $\overline{F_{\mathrm{t}}} / \mathrm{N}$ \\
\hline 5.0 & 0.39 & 0.2 & 1152.23 & 1135.57 \\
5.3 & 0.35 & 0.25 & 1091.25 & 1219.58 \\
5.6 & 0.31 & 0.26 & 1063.37 & 1323.53 \\
5.9 & 0.26 & 0.29 & 969.89 & 1286.08 \\
\hline
\end{tabular}

\section{Data Analysis}

Neck Thickness $\left(T_{\mathrm{n}}\right)$ and Undercut $\left(T_{\mathrm{u}}\right)$. Fig.6 is the variation curve of neck thickness and undercut. It can be seen from the figure, the neck thickness $\left(T_{\mathrm{n}}\right)$ decreases with the increasing of punch diameter $(d)$, and the data of experiment are slightly larger than those of simulation; However, the change of the undercut $\left(T_{\mathrm{u}}\right)$ is opposite, and the data of experiment is slightly less than the simulation value. It proves that using Deform software to simulate the riveting process is feasible, and the quality of clinched joint is good with sufficient neck thickness and undercut at the punch diameter $d=5.6 \mathrm{~mm}$.

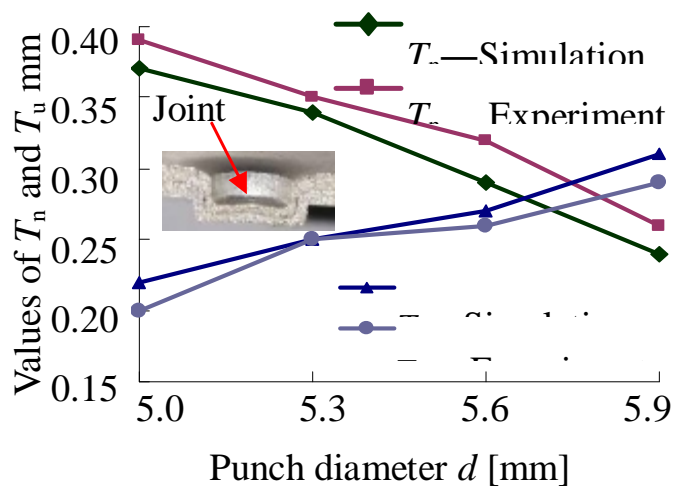

Fig.6 Graph of neck thickness $\left(T_{\mathrm{n}}\right)$ and undercut $\left(T_{\mathrm{u}}\right)$

Shearing Force $\left(\boldsymbol{F}_{\mathrm{s}}\right)$. Fig.7 is the change graph of shearing force. It can be seen from the figure, the shearing force of clinched point is decreased with the increasing of punch diameter, and shearing failure is the main failure form for joint. The result shows that the experimental values change is in accordance with the theoretical ones, and the experimental value has a little error to the theory value, because the former is out of considerations on engineering security, it proves that the experimental method has a good reliability. 
Tensile Force $\left(\boldsymbol{F}_{\mathrm{t}}\right)$. Fig.8 is the tensile force $F_{\mathrm{t}}$ graph of clinched points with punch diameter $d$ change. As can be seen from the figure, when $d \square 5.6 \mathrm{~mm}$, tensile force is increasing with the increasing of punch diameter, and stripping failure is the main failure form for joint; when $\mathrm{d}>5.6$ $\mathrm{mm}$, the tensile force decreases with the increasing of the punch diameter, and shearing failure is the main failure form for joint; and experimental value slightly less than the theoretical value with the increasing of punch diameter, but their change rules are consistent, the error is mainly that theoretical calculation takes into account the failure forms of clinched point-cutting and stripping, it can be judged by calculating smaller values under the actual situation. The results prove that the tensile force by the Eq. 9, Eq. 10 calculating is feasible.

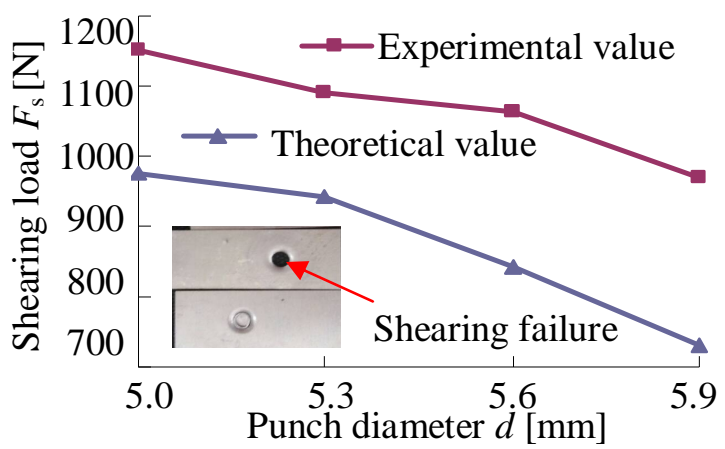

Fig.7 Graph of shearing force $\left(F_{\mathrm{s}}\right)$

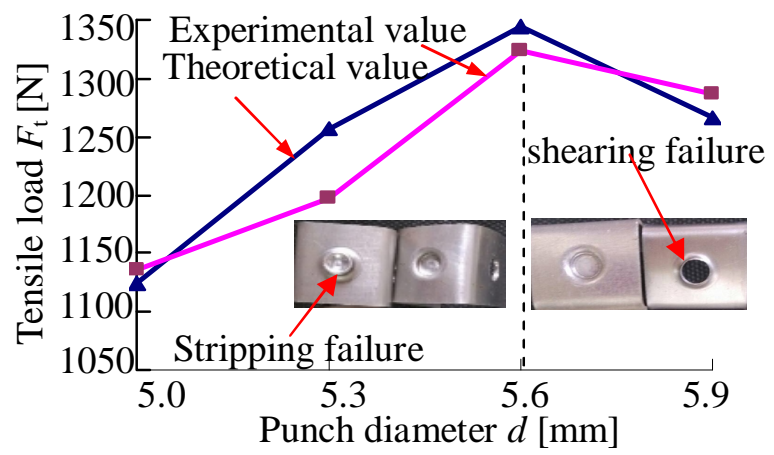

Fig.8 Graph of tensile force $\left(F_{\mathrm{t}}\right)$

\section{Conclusions}

By means of numerical simulation, theoretical analysis and experimental investigation, the force acting on joint and the joint strength analysis of the different punch diameter are done. The numerical results are in excellent agreement with the theoretical calculation and experimental results within the range of error permitting. Through the comparison with current experimental and theoretical values, on the condition that the other processing parameters are invariant, when the punch diameter $d=5.6 \mathrm{~mm}$, the joint strength is the largest. Through the analysis of results of theoretical calculation and the experiment, this article also verified that the formulas are valid.

\section{Acknowledgements}

The authors would like to acknowledge financial support from Guangxi Key Laboratory of Manufacturing System \& Advanced Manufacturing Technology (11-031-12_006) and Guangxi Natural Science Foundation (2015GXNSFBA139223).

\section{References}

[1] K.Q.Tang,. TOX connection technology in the application of the sheet metal connection, New Technology \& New Process, 2013, 2: 178-182(In Chinese)

[2] F. Lambiase, A. Di Ilio. Optimization of the clinching tools by means of integrated FE modeling and artificial intelligence techniques, J. Mater Process Tech. 12(2013)163-170 
[3] J.P. Varis, J. Lepisto. A simple testing-based procedure and simulation of the clinching process using finite element analysis for establishing clinching parameters, J. Thin-Walled StrucTures. 41(2013) 703-712

[4] Oudjenea M, Ben-Ayedb L, Delameziere A. et al. Shapeoptimization of clinching tools using the response surfacemethodology with Moving Least-Square approximation. J. Mater Process Tech. 209(2012)1875-1883

[5] Carbonniere J, Thuillier S, Sabourin F, et al, A Compari-son of the work hardening of metallic sheets in bending-unbending and simple shear. J. Mater Process Tech. 51 (2013)128-136 